\title{
An Approach for Integrated Analysis of Human Factors in Remote Handling Maintenance
}

\author{
Jianwen Guo, ${ }^{1}$ Zhenzhong Sun, ${ }^{1}$ Jiaxin He, ${ }^{1}$ Xuejun Jia, ${ }^{2}$ Hongjuan Li, ${ }^{3}$ Xiaohui Yan, \\ Haibin Chen, ${ }^{1}$ Hong Tang, ${ }^{2}$ and GuoHong $\mathrm{Wu}^{4}$ \\ ${ }^{1}$ School of Mechanical Engineering, Dongguan University of Technology, Dongguan 523808, China \\ ${ }^{2}$ Dongguan Neutron Science Center, Dongguan 523890, China \\ ${ }^{3}$ College of Mechanical Engineering, Zhejiang University, Hangzhou 310028, China \\ ${ }^{4}$ Dongguan Hengli Mould Technology Development Limited Company, Dongguan 523460, China
}

Correspondence should be addressed to Zhenzhong Sun; sunzz@dgut.edu.cn

Received 5 February 2016; Revised 29 May 2016; Accepted 29 May 2016

Academic Editor: Eugenijus Ušpuras

Copyright (C) 2016 Jianwen Guo et al. This is an open access article distributed under the Creative Commons Attribution License, which permits unrestricted use, distribution, and reproduction in any medium, provided the original work is properly cited.

\begin{abstract}
Considering dangerous environmental conditions, maintenance of radioactive equipment can be performed by remote handling maintenance (RHM) system. The RHM system is a sophisticated man-machine system. Therefore, human factors analysis is an inevitable aspect considered in guaranteeing successful and safe task performance. This study proposes an approach for integrated analysis of human factors in RHM so as to make the evaluating process more practical. In the approach, indicators of accessibility, health safety, and fatigue are analyzed using virtual human simulation technologies. The human error factors in the maintenance process are analyzed using the human error probability (HEP) based on the success likelihood index method- (SLIM-) analytic hierarchy process (AHP). The psychological factors level of maintenance personnel is determined with an expert scoring. The human factors for the entire RHM system are then evaluated using the interval method. An application example is present, and the application results show that the approach can support the evaluation of the human factors in RHM.
\end{abstract}

\section{Introduction}

Considering the environmental conditions for maintenance, radioactive equipment maintenance can be completed remotely without the need for any site personnel [1-3]. In such cases, remote handling maintenance (RHM) is necessary. RHM enables a person to manually handle work without being physically present at a work site through a manipulator or a robot [4]. The condition of components at the time of RHM is hard to predict. The unpredictability and complexity of the maintenance tasks will require human interaction during the maintenance process [5]. The RHM system is a sophisticated man-machine system that is human oriented [6]. Therefore, in the early phase of systems design, human factors analysis is an inevitable aspect considered in guaranteeing successful and safe task performance [7]. Therefore, studying the RHM system from the perspective of human factors engineering is of great significance in improving work efficiency, safety, and comfort [8].
Current human factors engineering studies on RHM need to be improved from the following aspects.

(1) Human factors evaluation in RHM is a complicated multi-index evaluation process with certain difficulties in quantitative and qualitative analyses. Therefore, this process requires highly effective evaluation methods.

(2) Conventional RHM evaluations usually need to be completed through actual maintenance work. The actual maintenance process is simulated on a physical prototype. Owing to their dependence on a specific physical prototype, conventional RHM evaluations can neither find defects in product design in a timely manner nor ensure the safety of maintenance personnel.

(3) RHM personnel inevitably make mistakes in longterm RHM, and their negative emotions may affect the safety and stability of RHM. Thus, reasonably 
estimating the effects of the errors and psychological factors of the evaluator on RHM is required.

To solve the above problems, the following are considered in this study.

(1) The method of fuzzy synthetic evaluating has been applied in various fields. The evaluating index is often specific value number. However the factors of RHM and the indexes are all uncertain. On one hand, the scores the evaluating experts applied are all uncertain. Besides, the evaluating level is often uncertain. It is obviously unsuitable to evaluate the human factors using the method based on specific value number. So the interval method $[9,10]$ is introduced in this paper.

(2) An ergonomic analysis is conducted by building a virtual maintenance environment and by introducing a virtual human model, thereby providing technical support for maintainability and maintenance analyses [11]. For instance, virtual human model can be used in determining whether there is enough room for people in different shape to perform their assembly or maintenance tasks; optimizing comfort, visibility, and access to controls of operators; and assisting engineers to optimize and validate workplace layout as per human factors evaluation.

(3) The human error probability (HEP) is the well-known parameter for describing human performance $[8,12]$. The HEP is the probability that an error will occur in a given task [13]. In maintenance activities, performance shaping factors (PSFs) are considered as the major contributors to HEP $[14,15]$. Success likelihood index method (SLIM) is one of the most flexible techniques and is widely used for quantifying the HEP by expert judgment $[16,17]$. In the SLIM, the judges identify the important PSF associated with a specific task; the contribution of each PSF to cause the human error is then judged and a relative weight is assigned. To reduce the inconsistency in the judgments of PSF, AHP-SLIM method has been developed [18]. The analytic hierarchy process (AHP) [19] is used to check the consistency among the experts while the SLIM is used to convert the likelihood into HEP.

In this study, an integrated human factors analysis approach is proposed for RHM. An evaluation indicator system of human factors is established for human factors analysis on RHM. In the approach, indicators of accessibility, health safety, and fatigue are analyzed using virtual human simulation technologies. The human error factors in the maintenance process are analyzed using the HEP based on the AHP-SLIM. The psychological cognition level of maintenance personnel is determined with an expert scoring. The human factors for the RHM system are then evaluated using the interval method. With radiation as the application object, the human factors in the maintenance process are analyzed, and corresponding improvement suggestions are provided. The application results show that the approach can support the evaluation of the human factors in RHM.
TABLE 1: Evaluation indicator system of human factors in RHM.

\begin{tabular}{lc}
\hline Criterion & Indicator \\
\hline Accessibility & $\begin{array}{c}\text { Visual accessibility } \\
\text { Operation accessibility }\end{array}$ \\
\hline Health safety & $\begin{array}{c}\text { Physical injuries } \\
\text { Radiation injuries }\end{array}$ \\
\hline Comfort & Fatigue at work \\
\hline Accuracy & HEP \\
\hline Internal factors & Psychological cognition \\
\hline
\end{tabular}

The remainder of the paper is organized as follows. Section 2 proposes an integrated human factors analysis approach for RHM. Section 3 shows how the proposed approach supports the human factors evaluation of the application example. Section 4 provides the conclusions and further works of the study.

\section{Integrated Human Factors Analysis Approach for RHM}

According to the features of the human factors in RHM, an approach for integrated analysis of human factors in RHM is designed, as shown in Figure 1. In the approach, RHM scheme is inputted. Evaluation indicator system of human factors in RHM is built. Data analysis of human factors in RHM is an integrated approach for getting data of evaluation. Human factors evaluation in RHM based on interval method is an approach for evaluating RHM scheme by the interval method. An approach for integrated analysis of human factors is illustrated as shown in Figure 1.

2.1. Evaluation Indicator System of Human Factors in RHM. An evaluation indicator system of human factors in RHM is established (shown in Table 1). The indicators are illustrated as follows.

(1) Accessibility. Operation accessibility requires sufficient room for maintenance. Visual accessibility must ensure that the maintenance personnel have a clear view of the objects in the maintenance process.

(2) Health Safety. The maintenance process should guarantee the safety of maintenance personnel and prevent the occurrence of physical injuries and radiation injuries.

(3) Comfort. Comfort at work, the workload, and difficulty at work must be properly determined to ensure that the maintenance personnel work persistently and maintenance quality and efficiency are achieved.

(4) Accuracy. Operational errors by maintenance personnel in the maintenance process, equipment, environment, and other factors must be avoided, and the HEP must be measured.

(5) Internal Factors. The psychological cognition of the RHM personnel at work must be evaluated. 


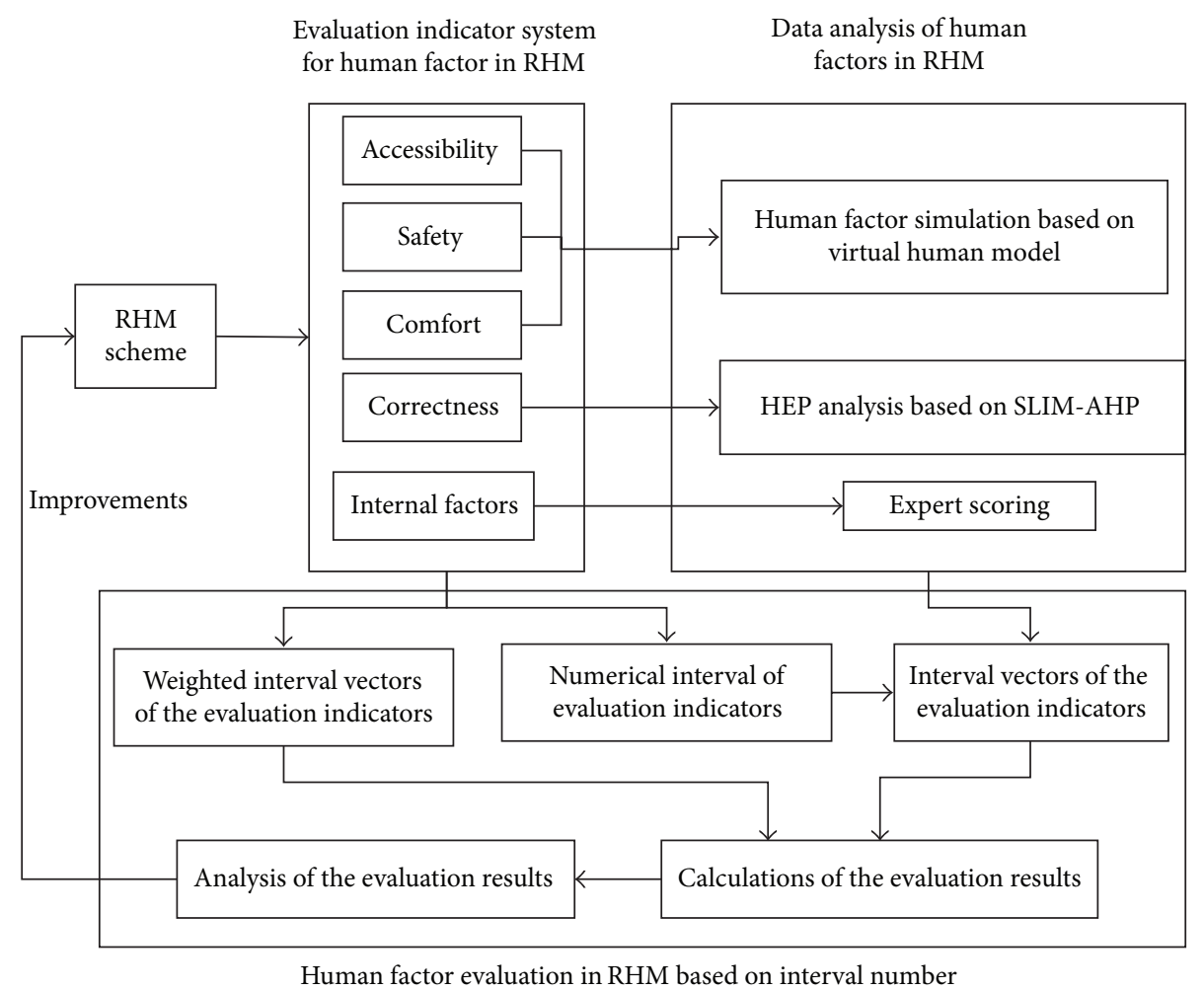

FIGURE 1: An integrated human factors analysis approach for RHM.

2.2. Data Analysis of Human Factors in RHM. The following three methods are adopted to analyze the evaluation data in the proposed approach.

(1) Human Factor Simulation Based on Virtual Human Model. The relevant indicators are quantified according to the simulation by the simulation platform and virtual human.

(2) HEP Analysis Based on AHP-SLIM. A series of influential PSFs is ascertained for RHM. In combination with AHP, the relative importance of PSF is provided, and the success likelihood index (SLI) is converted into the corresponding task failure probability to evaluate HEP in the RHM scheme.

(3) Expert Scoring. Internal factor evaluation in RHM mainly refers to evaluating the psychological cognition of the RHM personnel at work. In this study, the RHM personnel are quantitatively evaluated by expert scoring.

2.3. Human Factors Evaluation in RHM Based on Interval Method. The interval method can effectively overcome the numerical uncertainty caused by fuzziness [20]. The problems that are not estimated by deterministic mathematics can also be accurately expressed and calculated by the interval method [21]. The theory of interval method is introduced in evaluating the RHM scheme in this study to effectively analyze the human factors in the RHM scheme. The procedures are as follows.
(1) Numerical Interval of Evaluation Indicators. The numerical intervals of evaluation indicators are defined as five grades, as presented in Table 2.

(2) Weighted Interval Vectors. The weighted coefficients for the evaluation indicators are divided into 5 levels, as indicated in Table 3.

The initially weighted interval value is as follows:

$$
\overrightarrow{[\bar{Z}}]=\left(\left[\underline{Z_{1}}, \overline{Z_{1}}\right],\left[\underline{Z_{2}}, \overline{Z_{2}}\right], \ldots,\left[\underline{Z_{n}}, \overline{Z_{n}}\right]\right),
$$

where $n$ represents the number of evaluation indicators, $\left[Z_{i}, \overline{Z_{i}}\right]$ represents the initially weighted interval value of $i$ th indicator, and $\left[Z_{i}, \overline{Z_{i}}\right]$ falls into the weighted coefficient range, as given in Table 3 .

Fuzzy mathematics is adopted to process the indicators as follows:

$$
\left[\overline{E_{i}}\right]=\frac{\left(\left[\overline{Z_{i}}\right]-[\bar{A}]\right)}{([\bar{B}]-[\bar{A}])} \quad(1 \leq i \leq n),
$$

where $[\bar{A}]=[0.2,0.5]$ and $[\bar{B}]=[0.5,0.8]$.

The indicators are normalized as follows:

$$
\left[{\overline{E_{i}}}^{\prime}\right]=\frac{\left[\overline{E_{i}}\right]}{\sum_{i=1}^{n}\left[\overline{E_{i}}\right]} .
$$

The weighted interval vector after the processing is $[\overrightarrow{\bar{W}}]=$ $\left\{\left[\bar{E}_{i}^{\prime}\right] \mid 1 \leq i \leq n, i \in N\right\}$. 
TABLE 2: Numerical interval-based indicators.

\begin{tabular}{|c|c|c|c|c|c|c|}
\hline \multirow{2}{*}{ Criterion } & \multirow{2}{*}{ Indicator } & \multicolumn{5}{|c|}{$[0,1]$ Interval define } \\
\hline & & {$[0,0.2)$} & {$[0.2,0.4)$} & {$[0.4,0.6)$} & {$[0.6,0.8)$} & {$[0.8,1]$} \\
\hline \multirow{2}{*}{ Accessibility } & $\begin{array}{c}\text { Visual } \\
\text { accessibility }\end{array}$ & Very poor & Poor & Medium & Good & Very good \\
\hline & $\begin{array}{c}\text { Operation } \\
\text { accessibility }\end{array}$ & Very poor & Poor & Medium & Good & Very good \\
\hline & Physical injuries & Very serious & Serious & Medium & Small & Tiniest \\
\hline Health safety & $\begin{array}{c}\text { Radiation } \\
\text { injuries } \\
\text { (distance/m) }\end{array}$ & $0 \sim 0.2$ & $0.2 \sim 0.4$ & $0.4 \sim 0.6$ & $0.6 \sim 0.8$ & $0.8 \sim 1$ \\
\hline Comfort & $\begin{array}{c}\text { Fatigue at work } \\
\text { (RULA value) }\end{array}$ & 7 & $5 \sim 6$ & $3 \sim 4$ & 2 & 1 \\
\hline Correctness & HEP & $>0.08$ & $0.06 \sim 0.08$ & $0.04 \sim 0.06$ & $0.02 \sim 0.04$ & $<0.02$ \\
\hline Internal factors & $\begin{array}{c}\text { Psychological } \\
\text { cognition } \\
\text { (expert scoring) }\end{array}$ & $0 \sim 1$ & $1 \sim 2$ & $2 \sim 3$ & $3 \sim 4$ & $4 \sim 5$ \\
\hline
\end{tabular}

TABLE 3: Weighted coefficients for the evaluation indicators.

\begin{tabular}{lccccc}
\hline Grade & Class A & Class B & Class C & Class D & Class E \\
\hline Attribute & Especially important & Very important & More important & Important & General \\
Range & $(0.9,1.0]$ & $(0.8,0.9]$ & $(0.7,0.8]$ & $(0.6,0.7]$ & {$[0.5,0.6]$} \\
\hline
\end{tabular}

(3) Interval Vectors of the Evaluation Indicators. The value obtained by the data analysis module of human factors in RHM is converted into an interval method. The interval vector of the evaluation indicators is obtained as follows:

$$
\overrightarrow{[\vec{A}}]=\left(\left[\underline{a_{1}}, \overline{a_{1}}\right],\left[\underline{a_{2}}, \overline{a_{2}}\right], \ldots,\left[\underline{a_{n}}, \overline{a_{n}}\right]\right),
$$

where $n$ represents the number of evaluation indicators; $\left[a_{i}, \overline{a_{i}}\right]$ represents the interval value of $i$ th indicator.

(4) Calculations of the Evaluation Results. The calculations of the evaluation results are as follows:

$$
[\bar{R}]=[\overrightarrow{\bar{A}}] \cdot[\vec{W}]^{T}
$$

(5) Analysis of the Evaluation Results. The evaluation results are divided into five grades with corresponding interval methods assigned, as shown in Table 4.

\section{Application Example}

Figure 2 is a radioactive equipment. The green part of the equipment needs to be entirely replaced during maintenance. In the maintenance process, webcams are placed in a deep well. During operation, the RHM personnel need to perform maintenance operations with the help of long-handled tools and monitor the procedures on the computer screen (Figure 3).

3.1. Human Factor Analysis Based on Simulation. In this study, the simulation-based human factor evaluation platform is developed on the Delmia software [22], as illustrated

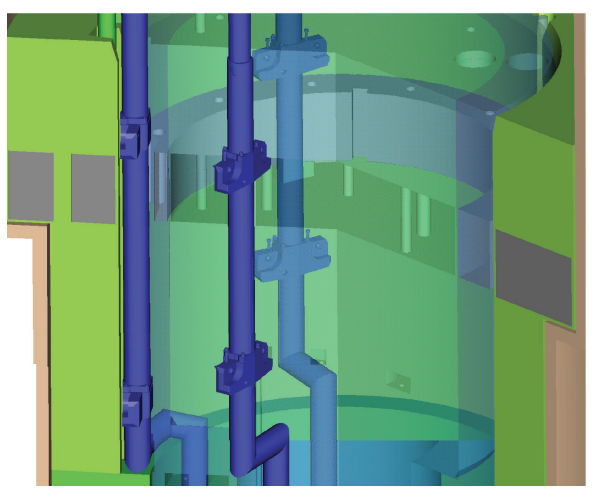

FIGURE 2: Sectional drawing of a radioactive equipment.

in Figure 4. The specific human body parameter design is shown in Figure 5.

(1) Visual Accessibility. According to the given maintenance scheme, the personnel should complete RHM by a computer screen. Visual accessibility is evaluated by observing whether the computer screen is in the best field of vision. The visual range provided by the simulation platform is shown in Figure 6. The computer screen displays the optimal view angle coverage for the RHM personnel. The RHM personnel can easily see the computer screen. Combined with the quantitative criteria for the indicators given in Table 2, visual accessibility may be quantitatively determined with a range of $(0.8,1]$.

(2) Operation Accessibility. Operation accessibility analysis requires the division of the maintenance area into three parts, 
TABLE 4: Criteria for evaluation grades.

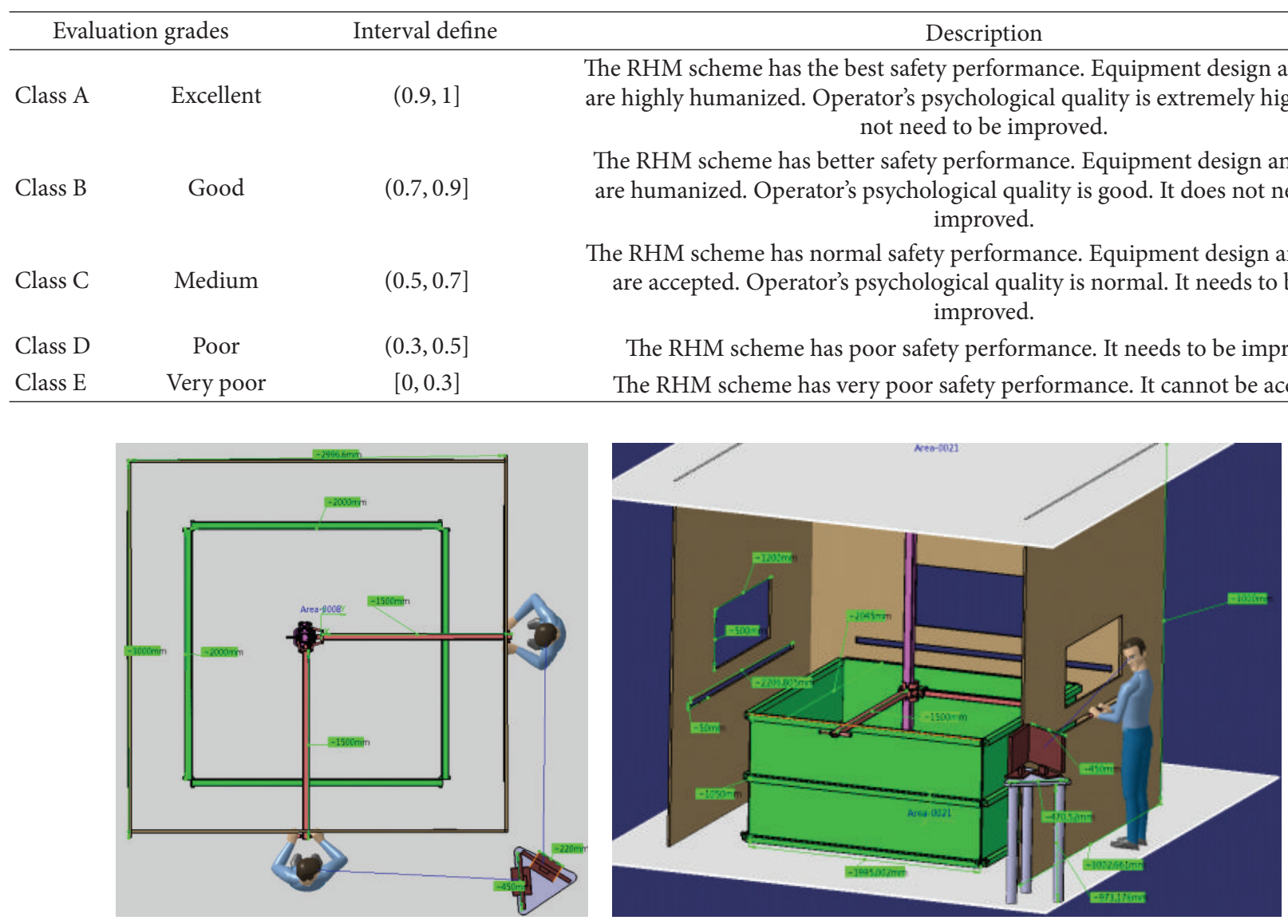

FIGURE 3: Teleoperation environment for the radioactive equipment.

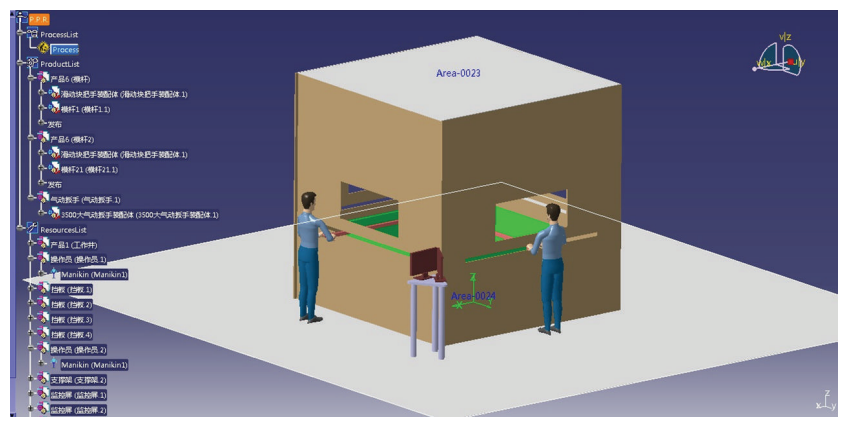

FIGURE 4: The simulation-based human factor evaluation platform.

namely, maintainable, maintainable boundary, and nonmaintainable zones. The maintenance areas where RHM tools can be reached are determined by the lengths, construction features, and operation modes of such tools.

According to the RHM scheme, an arm length of $18 \mathrm{~cm}$ is designed as the quantitative criterion for accessibility design. Both hands of the operation personnel can reach a 3D area, as shown in Figure 7. The operation personnel can hold the control stick by pushing their two hands into the wall. The scoring in Table 2 shows that operation accessibility is poor within the range of $(0.2,0.4]$.

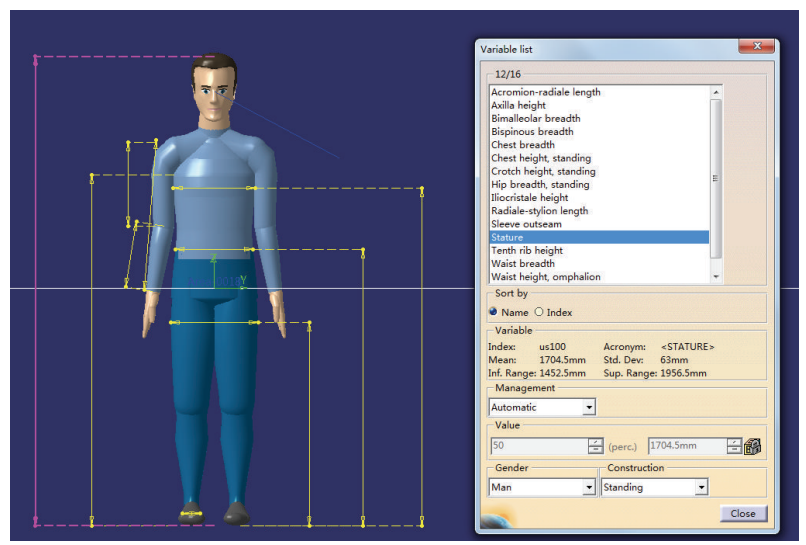

Figure 5: Personnel parameter design for RHM.

(3) Radiation Damage Evaluation. During RHM, the farther the distance from the radiation source is, the lower the radiation intensity is. The simulation results are illustrated in Figure 8, with a distance of $247.771 \mathrm{~mm}$ between the RHM personnel and the area with high radiation intensity. The quantitative criteria for the indicators given in Table 2 indicate that the quantized value of radiation damage is within the range of $(0.2,0.4]$. 


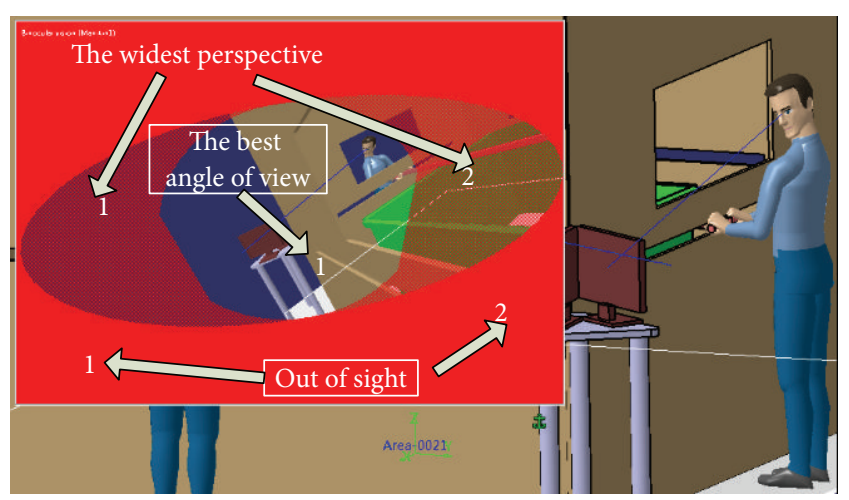

Figure 6: Visual range of the operation staff.

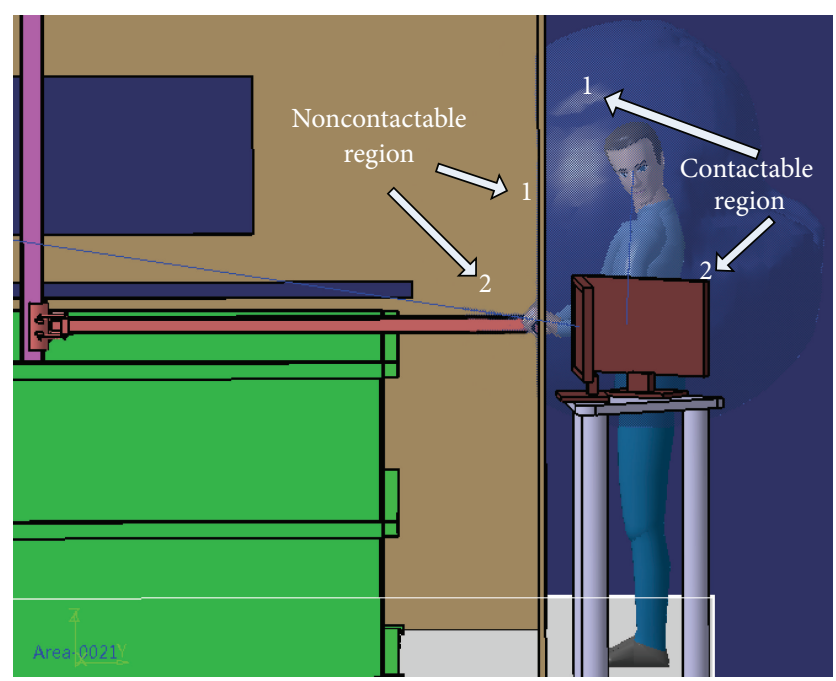

FIGURE 7: Accessibility coverage of the operation personnel.

(4) Physical Damage Evaluation. The effects of the contact between both hands of the personnel and the handle are simulated in Figure 9. In Figure 9(b), the area where the two hands of the personnel contact and collide with the handle is marked in red lines; the personnel are mostly prone to mechanical injuries. Figure 9(a) shows that the handle is so small that the hands of the personnel are squeezed and collide. From the quantitative criteria for the indicators in Table 2, we determined that the occurrence of physical injuries is high with quantized values of $(0.2,0.4]$.

(5) Comfort Evaluation. Rapid upper limb assessment (RULA) [23] is a reasonable and effective technique to evaluate work posture fatigue (or comfort). RULA can analyze and check the amount of exercise, static muscle work, work posture, and uninterrupted work time. Table 5 indicates that scores were determined by RULA by analyzing and summarizing individual comfort in terms of exercise amount, static muscle work, operating posture, and uninterrupted work time. A score of 1-2 (green) implies that this posture can be accepted for a short duration. A rating of 3-4 (yellow) indicates that the posture must be studied further or adjusted.
TABLE 5: RULA scoring rules.

\begin{tabular}{lcccccc}
\hline \multirow{2}{*}{ Section } & \multirow{2}{*}{ Score scope } & \multicolumn{6}{c}{ Relation between score and color } \\
& \multicolumn{7}{c}{1} & 2 & 3 & 4 & 5 & 6 \\
\hline Upper arm & $1-6$ & Green & Green & Yellow & Yellow Red Red \\
Forearm & $1-3$ & Green Yellow & Red \\
Wrist & $1-4$ & Green Yellow & Orange & Red \\
Rotate wrist & $1-2$ & Green & Red \\
Neck & $1-6$ & Green & Green & Yellow & Yellow Red Red \\
Breast & $1-6$ & Green & Green & Yellow & Yellow Red Red \\
\hline
\end{tabular}

A score of 5-6 (orange) means the posture must be adjusted as soon as possible. A rating of 7 (red) indicates that the posture must be adjusted immediately.

Figure 10 shows the RULA evaluation report that the operation personnel prepare using the simulation platform. The total score of posture is 7 (points), indicating that the posture load is relatively large and must be adjusted immediately. Using the quantitative criteria for the indicators in Table 2, the quantized value of fatigue is measured within the range of $[0,0.2]$.

3.2. HEP Based on SLIM-AHP. SLIM is a human error quantification method based on expert scoring. The basic assumption is that HEP is determined by the comprehensive effects of PSF. Analysis process of HEP based on AHP-SLIM is shown in Figure 11. Firstly the RHM operation errors are analyzed, and then human errors and key PSF (KPSF) are determined. AHP is proposed to determine the weighted value of KPSFs and evaluate the HEP. Finally, we calculate the SLI and HEP.

(1) Analysis of RHM Operation Errors. The operational errors in the preceding examples mainly include the following: missing parts; parts not assembled; parts assembled incorrectly; parts damaged, squeezed, scratched, and/or deformed by the improper torsion applied; and parts with radiation damages caused by ignored safety factors.

(2) Determination of Human Errors in RHM. RHM often involves various types of errors. By analyzing and investigating the errors in RHM, typical error categories in the sample applications are established (Table 6).

(3) Determination of KPSF. By interviewing experts and scholars familiar with RHM in a radiation environment, we identify four KPSFs that affect the errors of the RHM personnel in the sample applications. KPSFs that affect the errors of the RHM personnel are shown in Table 7.

(4) Determination of the Weighted Values of KPSF. Five experts and scholars familiar with RHM in a radiation environment are invited to score the KPSF through pairwise comparison method. The values of relative importance are shown in Table 8 . The results of the expert scoring by pairwise comparison method are provided in Table 9. The weighted values of KPSF are calculated with AHP. 


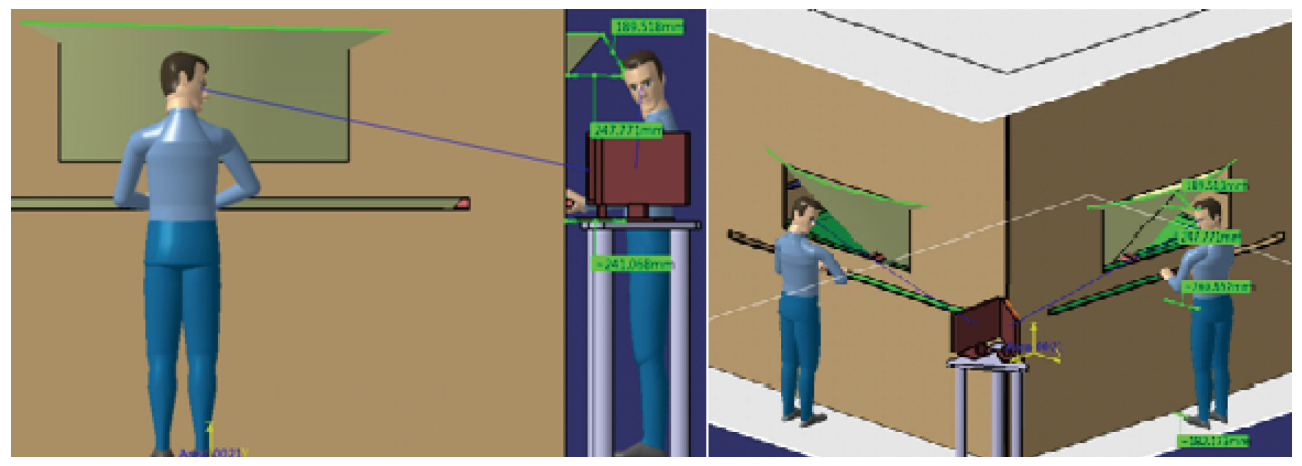

FiguRE 8: Layout of the radiation area.

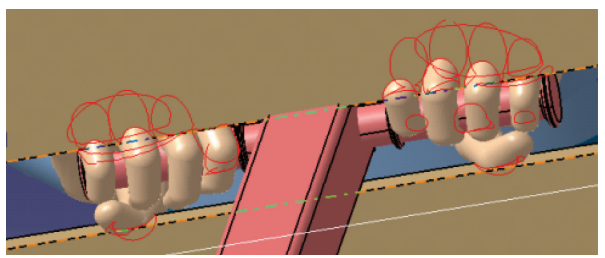

(a)

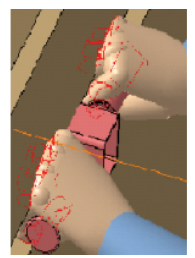

(b)

FIgURE 9: Simulation of the effects of the contact between both hands of the personnel and the handle.

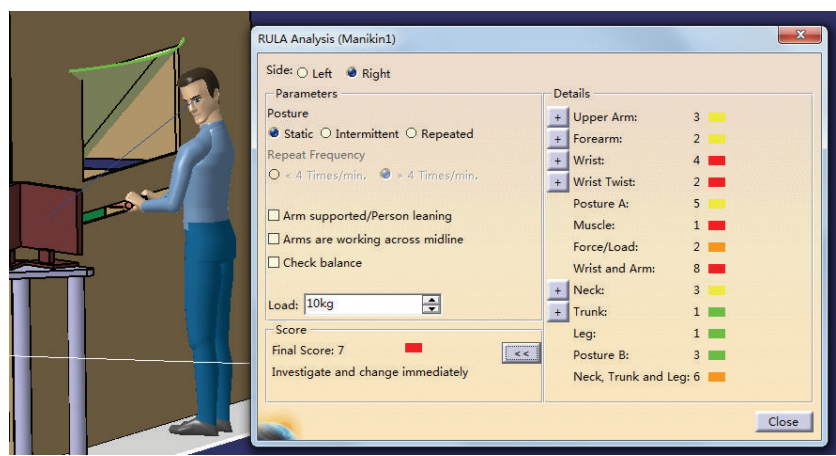

FIGURE 10: RULA evaluation report of the RHM personnel.

(1) Calculated consistency index, CI, is as follows:

$$
\mathrm{CI}=\frac{\lambda_{\max }-n}{n-1}=\frac{5.71-4}{4-1}=0.057
$$

where $\lambda_{\max }$ is eigenvalue of the valuation matrix; $n$ is the matrix size of the valuation matrix.

(2) Average random consistency index (RI) is as follows:

according to the literature [24], RI $=0.9$ (matrix size of the valuation matrix is 4 ).

(3) Weighted value of each factor is as follows:

$$
W_{\mathrm{KPSF}}=[0.424,0.181,0.332,0.063]^{T} .
$$

(4) Calculated consistency ratio (CR) of $\mathrm{CI}$ is as follows:

$\mathrm{CR}=\frac{\mathrm{CI}}{\mathrm{RI}}=\frac{0.057}{0.9}=0.064<0.1$ (passed one time) .
(5) HEP Evaluation Based on KPSF. The five experts are also requested to determine which error is likely to occur under the condition of KPSF. Each of the experts may obtain a KPSF-related matrix. The AHP calculations (Tables 10-13) are based on the scoring results of one of the experts.

(6) Calculation of the Success Likelihood Factor. The SLI is calculated with the weighted values of KPSF and HEP based on KPSF using the following calculation formula:

$$
\mathrm{SLI}_{j}=\sum_{i}^{4} W_{\mathrm{KPSF}_{i}} A_{i j} \quad(j=1,2,3,4,5,6),
$$

where $\mathrm{SLI}_{j}$ refers to the success likelihood factor of the $j$ th typical error category, $W_{\mathrm{KPSF}_{i}} \in W_{\mathrm{KPSF}}$ and $A_{i j}$ refers to the weighted value of the $\mathrm{KPSF}_{i}$ of the $j$ th typical error category.

The calculation results are shown in Table 14.

Similarly, the values of SLI estimated based on the judgment results of the remaining four experts through the preceding calculation procedures are shown in Table 15.

(7) Calculation of HEP. The average of each of the SLIs is calculated (Table 16). To convert the SLI of every task into the corresponding probability value, the following logarithmic relation is established:

$$
\lg \mathrm{HEP}=a \mathrm{SLI}+b,
$$

where " $a$ " and " $b$ " are the constants to be determined.

According to the calculation results of SLI, Error $A_{5}$ with the minimum SLI and Error $A_{6}$ with the maximum SLI are selected as two boundary points for solving the constants (" $a$ " and " $b$ "). The absolute probability judgment (APJ) implies 


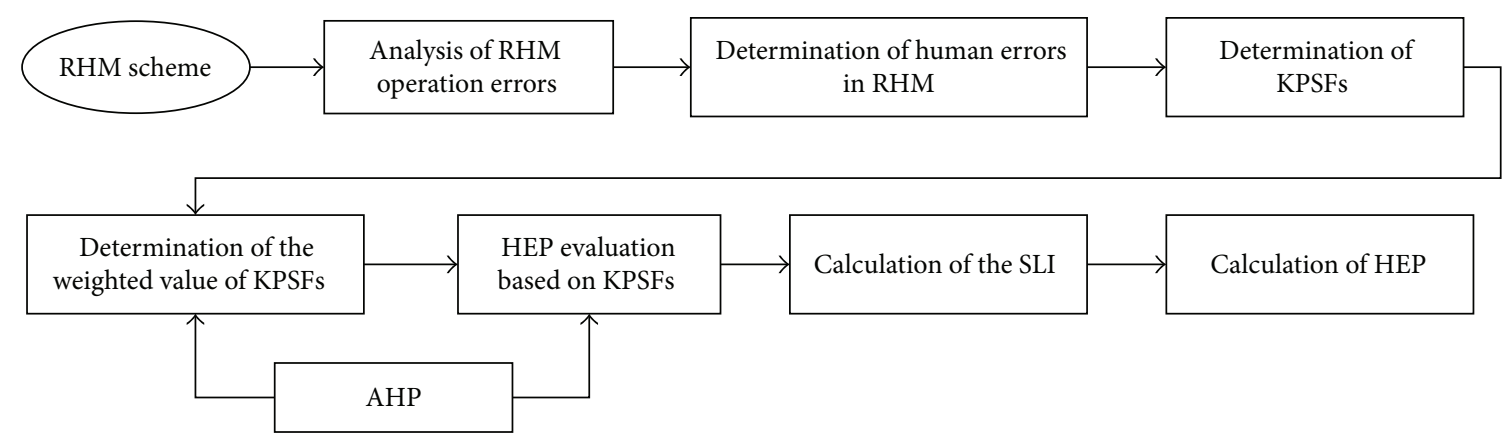

FIGURE 11: Analysis process of HEP based on AHP-SLIM.

TABLE 6: Six typical human errors in the sample applications.

\begin{tabular}{lcr}
\hline SN & Human errors & Detailed description of the errors \\
\hline$A_{1}$ & Missing bolts & The RHM personnel forgot to mount the bolts. \\
$A_{2}$ & Torque exceeding the limited value & Parts assembled incorrectly \\
$A_{3}$ & Operations in wrong sequence & Excessive torque is applied when using the pneumatic wrench. \\
$A_{4}$ & Tools used wrongly & Other parts are assembled mistakenly. \\
$A_{5}$ & Screws not tightened & The operational sequence is reversed. \\
$A_{6}$ & Tools are incorrectly used.
\end{tabular}

that $P_{A_{5}}=0.004$ and $P_{A_{6}}=0.024$, thus obtaining $a=4.833$ and $b=-2.799$.

The HEP value of the entire RHM can be obtained by the sum of HEP:

$$
\begin{aligned}
\mathrm{HEP}= & 0.0205+0.0078+0.0060+0.0136+0.0040 \\
& +0.0240=0.0759
\end{aligned}
$$

As shown in Table 2, the quantized value of HEP is within the range of $(0.2,0.4]$.

3.3. Internal Factor Evaluation. Internal factor evaluation in RHM mainly refers to evaluating the psychological cognition of the RHM personnel at work. In this study, the RHM personnel's psychological cognition is quantitatively evaluated by expert scoring, as shown in Table 17. Five experts are invited to score the inner feelings of the RHM personnel after long-term operation. The results are provided in Table 18. The average of the results of the five-expert scoring implies that the psychological cognition is 3.4 (points). According to the indicators given in Table 1 , the quantized value of psychological cognition is within the range of $(0.6,0.8]$.

3.4. Human Factor Evaluation in RHM Based on the Interval Method. The quantized values of the seven indicators are summarized, with the vectors illustrated by the interval method as follows:

$$
\begin{aligned}
& \overrightarrow{[\vec{A}]}=((0.8,1],(0.2,0.4],(0.2,0.4],(0.2,0.4],[0,0.2], \\
& \quad(0.2,0.4],(0.6,0.8]) .
\end{aligned}
$$

By expert scoring, we have the following initially weighted interval vectors:

$$
\begin{gathered}
\overrightarrow{[\vec{Z}]}=([0.8,0.9],[0.8,0.9],[0.7,0.8],[0.6,0.7], \\
[0.7,0.8],[0.6,0.7],[0.6,0.7]) .
\end{gathered}
$$

The weighted interval vectors of the indicators after fuzzy normalization are

$$
\begin{gathered}
\overrightarrow{[\bar{W}]}=\left(\left[\frac{2}{17}, \frac{3}{10}\right],\left[\frac{2}{17}, \frac{3}{10}\right],\left[\frac{3}{34}, \frac{1}{4}\right],\left[\frac{1}{17}, \frac{1}{5}\right],\right. \\
\left.\left[\frac{3}{34}, \frac{1}{4}\right],\left[\frac{1}{17}, \frac{1}{5}\right],\left[\frac{1}{17}, \frac{1}{5}\right]\right) .
\end{gathered}
$$

The values of the human factor analysis on RHM are as follows:

$$
[\bar{R}]=[\overrightarrow{\bar{A}}] \cdot[\vec{W}]=[0.1,0.3]
$$

In contrast to Table 4 (criteria for evaluation grades), the fuzzy interval evaluation results on the safety performance of the RHM scheme are of Grade E, namely, very poor. The RHM scheme requires further improvements in equipment, environment, and psychological diathesis of RHM personnel (with HEP in RHM).

\section{Conclusions and Further Works}

In this paper, an integrated human factors analysis approach is developed to evaluate human factors in the RHM. Compared with the conventional RHM evaluations approach, the proposed approach has the following advantages. 
TABLE 7: KPSF that affect the errors of the RHM personnel.

\begin{tabular}{|c|c|c|}
\hline Code & KPSF & Interpretation \\
\hline $\mathrm{KPSF}_{1}$ & Experience and knowledge & $\begin{array}{l}\text { With extensive knowledge and experience in RHM, the RHM personnel can avoid most of } \\
\text { the errors. }\end{array}$ \\
\hline $\mathrm{KPSF}_{2}$ & Safety consciousness & The level of safety consciousness concerns the prudence and importance of RHM. \\
\hline $\mathrm{KPSF}_{3}$ & Working environment & The rational placement of tools significantly influences the errors of the RHM personnel. \\
\hline $\mathrm{KPSF}_{4}$ & Workload & $\begin{array}{l}\text { Work difficulty or work posture that does not match the personnel's ability may exert } \\
\text { physiological and/or psychological pressure on the RHM personnel, thereby increasing HEP. }\end{array}$ \\
\hline
\end{tabular}

TABLE 8: Values of relative importance.

\begin{tabular}{lc}
\hline Value & Importance \\
\hline 1 & Two factors of the same importance \\
3 & One of the two factors is not important to the other \\
5 & One of the two factors is relatively important to the other \\
7 & One of the two factors is very important to the other \\
9 & One of the two factors is extremely important to the other \\
$2,4,6,8$ & Median value of two adjacent values \\
\hline
\end{tabular}

TABLE 9: Evaluation matrix for the evaluation factors.

\begin{tabular}{lcccc}
\hline Estimated value & $\mathrm{KPSF}_{1}$ & $\mathrm{KPSF}_{2}$ & $\mathrm{KPSF}_{3}$ & $\mathrm{KPSF}_{4}$ \\
\hline $\mathrm{KPSF}_{1}$ & 1 & 2 & 2 & 5 \\
$\mathrm{KPSF}_{2}$ & $1 / 2$ & 1 & $1 / 3$ & 4 \\
$\mathrm{KPSF}_{3}$ & $1 / 2$ & 3 & 1 & 5 \\
$\mathrm{KPSF}_{4}$ & $1 / 5$ & $1 / 4$ & $1 / 5$ & 1 \\
\hline
\end{tabular}

TABLE 10: Evaluation matrix under the condition of $\mathrm{KPSF}_{1}{ }^{\mathrm{a}}$.

\begin{tabular}{lcccccc}
\hline KPSF $_{1}$ & $A_{1}$ & $A_{2}$ & $A_{3}$ & $A_{4}$ & $A_{5}$ & $A_{6}$ \\
\hline$A_{1}$ & 1 & 2 & 3 & 2 & 4 & $1 / 2$ \\
$A_{2}$ & $1 / 2$ & 1 & 2 & 1 & 2 & 1 \\
$A_{3}$ & $1 / 3$ & $1 / 2$ & 1 & $1 / 2$ & 3 & $1 / 2$ \\
$A_{4}$ & $1 / 2$ & 1 & 2 & 1 & 5 & 1 \\
$A_{5}$ & $1 / 4$ & 1 & 2 & $1 / 5$ & 1 & $1 / 2$ \\
$A_{6}$ & 2 & 1 & 2 & 1 & 2 & 1 \\
${ }^{\mathrm{a}} \lambda_{\max }=6.365, n=6, \mathrm{CI}=0.073, \mathrm{RI}=1.24, \mathrm{CR}=0.059<0.1$, and $W_{1}=$ \\
{$[0.255,0.169,0.106,0.197,0.060,0.218]^{T}$.}
\end{tabular}

TABLE 11: Evaluation matrix under the condition of $\mathrm{KPSF}_{2}{ }^{\mathrm{a}}$.

\begin{tabular}{lcccccc}
\hline $\mathrm{KPSF}_{2}$ & $A_{1}$ & $A_{2}$ & $A_{3}$ & $A_{4}$ & $A_{5}$ & $A_{6}$ \\
\hline$A_{1}$ & 1 & 2 & 3 & 2 & 3 & $1 / 3$ \\
$A_{2}$ & $1 / 2$ & 1 & 2 & 1 & 2 & 1 \\
$A_{3}$ & $1 / 3$ & $1 / 2$ & 1 & $1 / 2$ & 3 & $1 / 2$ \\
$A_{4}$ & $1 / 2$ & 1 & 2 & 1 & 5 & 1 \\
$A_{5}$ & $1 / 3$ & 1 & 2 & $1 / 5$ & 1 & $1 / 2$ \\
$A_{6}$ & 3 & 1 & 2 & 1 & 2 & 1 \\
\hline
\end{tabular}

${ }^{\mathrm{a}} \lambda_{\max }=6.525, n=6, \mathrm{CI}=0.105, \mathrm{RI}=1.24, \mathrm{CR}=0.085<0.1$, and $W_{2}=$ $[0.230,0.170,0.107,0.199,0.064,0.230]^{T}$.

(1) Human factors evaluation in RHM based on interval method is introduced to solve the numerical uncertainties arising from the fuzziness in human factors evaluation.
TABLE 12: Evaluation matrix under the condition of $\mathrm{KPSF}_{3}{ }^{\mathrm{a}}$.

\begin{tabular}{lcccccc}
\hline $\mathrm{KPSF}_{3}$ & $A_{1}$ & $A_{2}$ & $A_{3}$ & $A_{4}$ & $A_{5}$ & $A_{6}$ \\
\hline$A_{1}$ & 1 & 3 & 2 & 2 & 3 & $1 / 3$ \\
$A_{2}$ & $1 / 3$ & 1 & 1 & $1 / 2$ & 2 & 1 \\
$A_{3}$ & $1 / 2$ & $1 / 2$ & 1 & $1 / 2$ & 4 & $1 / 2$ \\
$A_{4}$ & $1 / 2$ & 2 & 3 & 1 & 5 & 1 \\
$A_{5}$ & $1 / 3$ & $1 / 3$ & $1 / 4$ & $1 / 5$ & 1 & $1 / 2$ \\
$A_{6}$ & 3 & 1 & 2 & 1 & 2 & 1 \\
${ }^{\mathrm{a}} \lambda_{\max }=6.575, n=6, \mathrm{CI}=0.115, \mathrm{RI}=1.24, \mathrm{CR}=0.09359<0.1$, and $W_{3}=$ \\
{$[0.229,0.126,0.135,0.222,0.061,0.229]^{T}$.}
\end{tabular}

TABLE 13: Evaluation matrix under the condition of $\mathrm{KPSF}_{4}{ }^{\mathrm{a}}$.

\begin{tabular}{lcccccc}
\hline $\mathrm{KPSF}_{4}$ & $A_{1}$ & $A_{2}$ & $A_{3}$ & $A_{4}$ & $A_{5}$ & $A_{6}$ \\
\hline$A_{1}$ & 1 & $1 / 3$ & 2 & $1 / 2$ & 3 & $1 / 2$ \\
$A_{2}$ & 3 & 1 & 5 & 1 & 5 & 1 \\
$A_{3}$ & $1 / 2$ & $1 / 2$ & 1 & $1 / 2$ & 4 & $1 / 3$ \\
$A_{4}$ & 2 & 2 & 2 & 1 & 5 & 1 \\
$A_{5}$ & $1 / 3$ & $1 / 5$ & $1 / 4$ & $1 / 5$ & 1 & $1 / 3$ \\
$A_{6}$ & 2 & 1 & 3 & 1 & 3 & 1 \\
\hline
\end{tabular}

${ }^{\mathrm{a}} \lambda_{\max }=6.245, n=6, \mathrm{CI}=0.049, \mathrm{RI}=1.24, \mathrm{CR}=0.040<0.1$, and $W_{4}=$ $[0.124,0.286,0.089,0.230,0.045,0.226]^{T}$.

(2) Human factors analysis based on simulation and virtual human is used to support human factors evaluation in the RHM design state. And it does not need a physical prototype.

(3) The human error factors in the maintenance process are analyzed using the HEP based on the AHP-SLIM. The AHP is used to check the consistency among the experts while the SLIM is used to convert the likelihood into HEPs.

In the approach, the evaluation indicator system of human factors in RHM is the key to the analysis of human factors in RHM. As there are many factors that affect the human factors in RHM, only the perfect evaluation indicator system can get closer to the results of the facts. Furthermore, we will improve the evaluation indicator system according to different application scenarios.

\section{Competing Interests}

The authors declare that there is no conflict of interests regarding the publication of this paper. 
TABLE 14: Calculation results of SLI.

\begin{tabular}{lllll}
\hline$W_{\mathrm{KPSF}_{1}}=0.424$ & $W_{\mathrm{KPSF}_{2}}=0.181$ & $W_{\mathrm{KPSF}_{3}}=0.332$ & $W_{\mathrm{KPSF}_{4}}=0.063$ & $\mathrm{SLI}_{j}=\sum_{i}^{4} W_{i} A_{i j}$ \\
\hline$A_{11}=0.255$ & $A_{21}=0.230$ & $A_{31}=0.229$ & $A_{41}=0.124$ & $A_{42}=0.286$ \\
$A_{12}=0.169$ & $A_{22}=0.170$ & $A_{32}=0.126$ & $A_{43}=0.089$ & $\mathrm{SLI}_{2}=0.234$ \\
$A_{13}=0.106$ & $A_{23}=0.107$ & $A_{33}=0.135$ & $A_{44}=0.230$ & $\mathrm{SLI}_{3}=0.115$ \\
$A_{14}=0.197$ & $A_{24}=0.199$ & $A_{34}=0.222$ & $A_{45}=0.045$ & $\mathrm{SLI}_{4}=0.208$ \\
$A_{15}=0.060$ & $A_{25}=0.064$ & $A_{35}=0.061$ & $A_{46}=0.226$ & $\mathrm{SLI}_{5}=0.060$ \\
$A_{16}=0.218$ & $A_{26}=0.230$ & $A_{36}=0.229$ & $\mathrm{SLI}_{6}=0.224$ \\
\hline
\end{tabular}

TABLE 15: Values of SLI estimated based on the results of the five experts.

\begin{tabular}{lcccc}
\hline SLI of Expert 1 & SLI of Expert 2 & SLI of Expert 3 & SLI of Expert 4 & SLI of Expert 5 \\
\hline 0.234 & 0.230 & 0.227 & 0.236 & 0.153 \\
0.162 & 0.124 & 0.142 & 0.104 & 0.225 \\
0.115 & 0.108 & 0.105 & 0.117 & 0.135 \\
0.208 & 0.221 & 0.211 & 0.095 & 0.207 \\
0.060 & 0.103 & 0.072 & 0.302 & 0.083 \\
0.224 & 0.225 & 0.230 & & 0.241 \\
\hline
\end{tabular}

TABLE 16: Averages of SLI and HEP.

\begin{tabular}{lcccc}
\hline Number & Item & Average of SLI & Average of HEP & Sorted by error probability \\
\hline$A_{1}$ & Missing bolts & 0.230 & 0.0205 & 2 \\
$A_{2}$ & Torque exceeding the limited value & 0.143 & 0.0078 & 4 \\
$A_{3}$ & Parts assembled incorrectly & 0.119 & 0.0060 & 5 \\
$A_{4}$ & Operations in wrong sequence & 0.193 & 0.0136 & 3 \\
$A_{5}$ & Tools used wrongly & 0.083 & 0.0040 & 6 \\
$A_{6}$ & Screws not tightened & 0.244 & 0.0240 & 1 \\
\hline
\end{tabular}

TABLE 17: Psychological cognition scoring system.

\begin{tabular}{lcccc}
\hline Performance & $\begin{array}{c}\text { Depressed and discontented, } \\
\text { with feelings expressed by } \\
\text { body language }\end{array}$ & $\begin{array}{c}\text { Irritable, with feelings } \\
\text { expressed by verbal } \\
\text { language }\end{array}$ & $\begin{array}{c}\text { Fidgety and } \\
\text { depressed }\end{array}$ & $\begin{array}{c}\text { Languid and } \\
\text { fatigued }\end{array}$ \\
\hline Scoring (points) & 1 & 2 & 3 & 4 \\
\hline
\end{tabular}

TABLE 18: Expert scoring results.

\begin{tabular}{lccccc}
\hline Expert & Expert 1 & Expert 2 & Expert 3 & Expert 4 & Expert 5 \\
\hline Scoring (points) & 4 & 3 & 4 & 2 & 4 \\
\hline
\end{tabular}

\section{Acknowledgments}

The study was supported by the National Natural Science Foundation of China (Grant no. 71201026), the Natural Science Foundation of Guangdong (no. 2015A030310274, no. 2015A030310415, and no. 2015A030310315), the Project of Department of Education of Guangdong Province (no. 2013KJCX0179, no. 2014KTSCX184, and no. 2014KGJHZ014), the Development Program for Excellent Young Teachers in Higher Education Institutions of Guangdong Province (no. Yq2013156), the Dongguan Universities and Scientific Research Institutions Science and Technology Project (no. 2014106101007), and the Dongguan Social Science and Technology Development Project (no. 2013108101011).

\section{References}

[1] I. Ribeiro, C. Damiani, A. Tesini, S. Kakudate, M. Siuko, and C. Neri, "The remote handling systems for ITER," Fusion Engineering and Design, vol. 86, no. 6-8, pp. 471-477, 2011.

[2] Z. Zhou, D. Yao, and P. Zi, “The research activities on remote handling system for CFETR," Journal of Fusion Energy, vol. 34, no. 2, pp. 232-237, 2015.

[3] K. Kershaw, B. Feral, J.-L. Grenard et al., "Remote inspection, measurement and handling for maintenance and operation at CERN," International Journal of Advanced Robotic Systems, vol. 10, article 382, pp. 1-11, 2013.

[4] J. Guo, H. Tang, Z. Sun et al., "An improved shuffled frog leaping algorithm for assembly sequence planning of remote handling maintenance in radioactive environment," Science and Technology of Nuclear Installations, vol. 2015, Article ID 516470, 14 pages, 2015.

[5] European Fusion Development Agreement (EFDA), https:// www.euro-fusion.org/fusion/jet-remote-handling/. 
[6] G. Y. R. Schropp, C. J. M. Heemskerk, A. M. L. Kappers, W. M. B. Tiest, B. S. Q. Elzendoorn, and D. Bult, "Influence of visual feedback on human task performance in ITER remote handling," Fusion Engineering and Design, vol. 87, no. 5-6, pp. 808-812, 2012.

[7] H. Boessenkool, D. A. Abbink, C. J. M. Heemskerk et al., "Analysis of human-in-the-loop tele-operated maintenance inspection tasks using VR," Fusion Engineering and Design, vol. 88, no. 9-10, pp. 2164-2167, 2013.

[8] S.-G. Qiu, Q.-C. He, X.-M. Fan, and D.-L. Wu, "Virtual human hybrid control in virtual assembly and maintenance simulation," International Journal of Production Research, vol. 52, no. 3, pp. 867-887, 2014.

[9] J. Geng, D. Zhou, C. Lv, and Z. Wang, "A modeling approach for maintenance safety evaluation in a virtual maintenance environment," Computer-Aided Design, vol. 45, no. 5, pp. 937949, 2013.

[10] L. V. Kolev, Interval Methods for Circuit Analysis, World Scientific, Singapore, 1993.

[11] L. Jaulin, M. Kieffer, O. Didrit, and E. Walter, Applied Interval Analysis: With Examples in Parameter and State Estimation, Robust Control and Robotics, Springer, London, UK, 2001.

[12] W. Preischl and M. Hellmich, "Human error probabilities from operational experience of German nuclear power plants," Reliability Engineering \& System Safety, vol. 109, pp. 150-159, 2013.

[13] W. Preischl and M. Hellmich, "Human error probabilities from operational experience of German nuclear power plants, part II," Reliability Engineering \& System Safety, vol. 148, pp. 44-56, 2016.

[14] A. D. Swain and H. E. Guttmann, "Handbook of human reliability analysis with emphasis on nuclear power plant applications," Final Report NUREG/CR-1278, U.S. Nuclear Regulatory Commission, 1983.

[15] A. Noroozi, F. Khan, S. Mackinnon, P. Amyotte, and T. Deacon, "Determination of human error probabilities in maintenance procedures of a pump," Process Safety and Environmental Protection, vol. 92, no. 2, pp. 131-141, 2014.

[16] R. Abbassi, F. Khan, V. Garaniya, S. Chai, C. Chin, and K. A. Hossain, "An integrated method for human error probability assessment during the maintenance of offshore facilities," Process Safety and Environmental Protection, vol. 94, pp. 172-179, 2015.

[17] D. E. Embrey, P. C. Humphreys, E. A. Rosa, B. Kirwan, and K. Rea, "SLIM-MAUD: an approach to assessing human error probabilities using structured expert judgment," Tech. Rep. NUREG/CR-3518, Department of Nuclear Energy, Brookhaven National Laboratory, US NRC, 1984.

[18] M. Grozdanovic, "Usage of human reliability quantification methods," International Journal of Occupational Safety and Ergonomics, vol. 11, no. 2, pp. 153-159, 2015.

[19] K. S. Park and J. I. Lee, "A new method for estimating human error probabilities: AHP-SLIM," Reliability Engineering and System Safety, vol. 93, no. 4, pp. 578-587, 2008.

[20] T. L. Saaty, "Decision-making with the AHP: why is the principal eigenvector necessary," European Journal of Operational Research, vol. 145, no. 1, pp. 85-91, 2003.

[21] T. Shaocheng, "Interval number and fuzzy number linear programmings," Fuzzy Sets \& Systems, vol. 66, no. 3, pp. 301306, 1994.
[22] J. Wei, H. Chen, Y. Chen et al., "China spallation neutron source: design, R\&D, and outlook," Nuclear Instruments and Methods in Physics Research Section A: Accelerators, Spectrometers, Detectors and Associated Equipment, vol. 600, no. 1, pp. 10-13, 2009.

[23] Dassault Systemes DELMIA, http://www.3ds.com/productsservices/delmia/.

[24] L. McAtamney and E. N. Corlett, "RULA: a survey method for the investigation of work-related upper limb disorders," Applied Ergonomics, vol. 24, no. 2, pp. 91-99, 1993. 

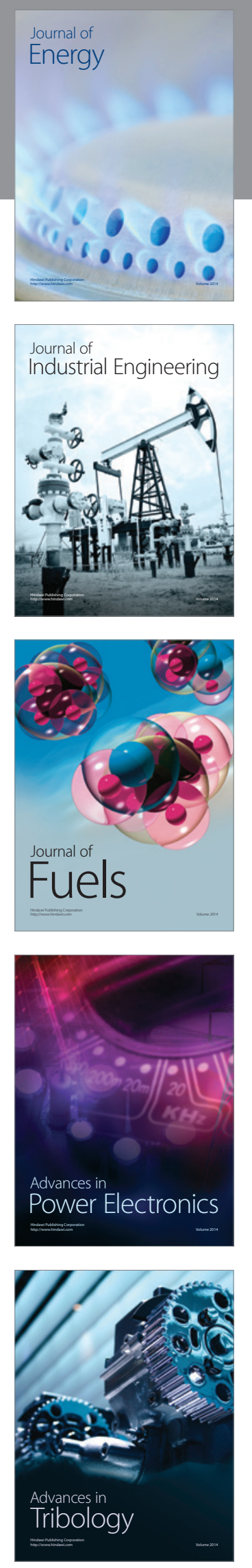
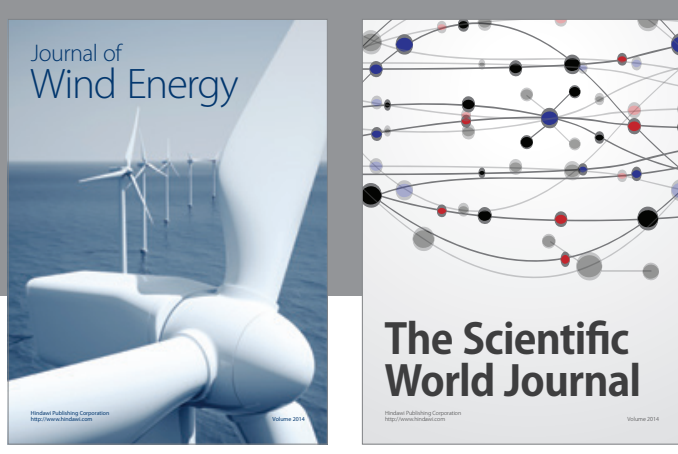

The Scientific World Journal
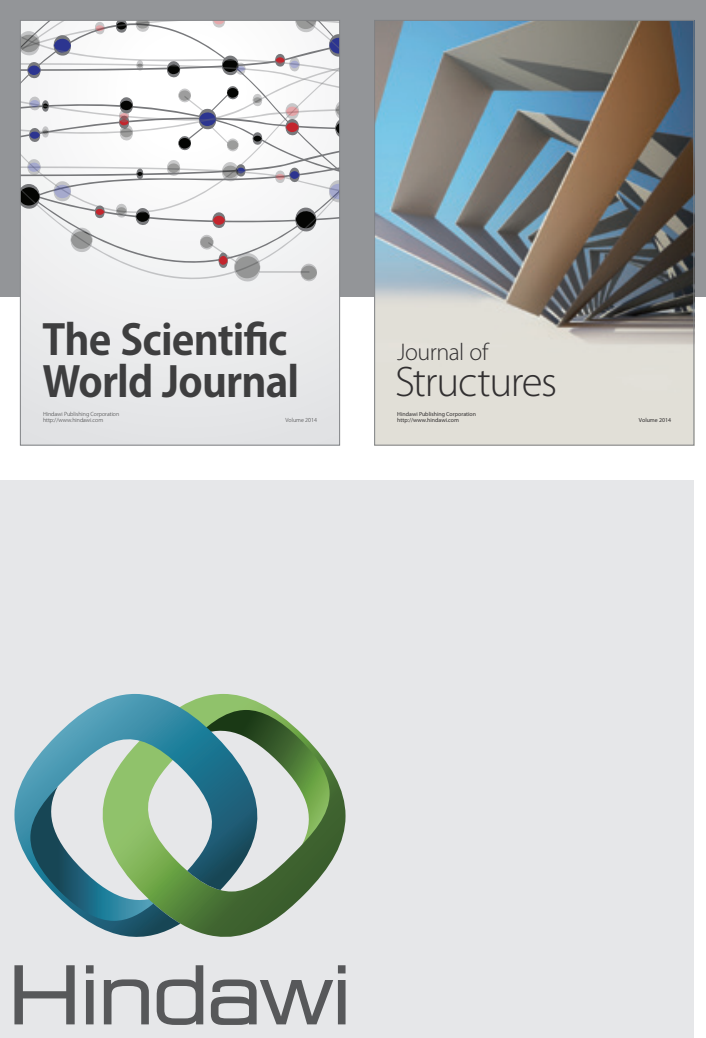

Submit your manuscripts at

http://www.hindawi.com
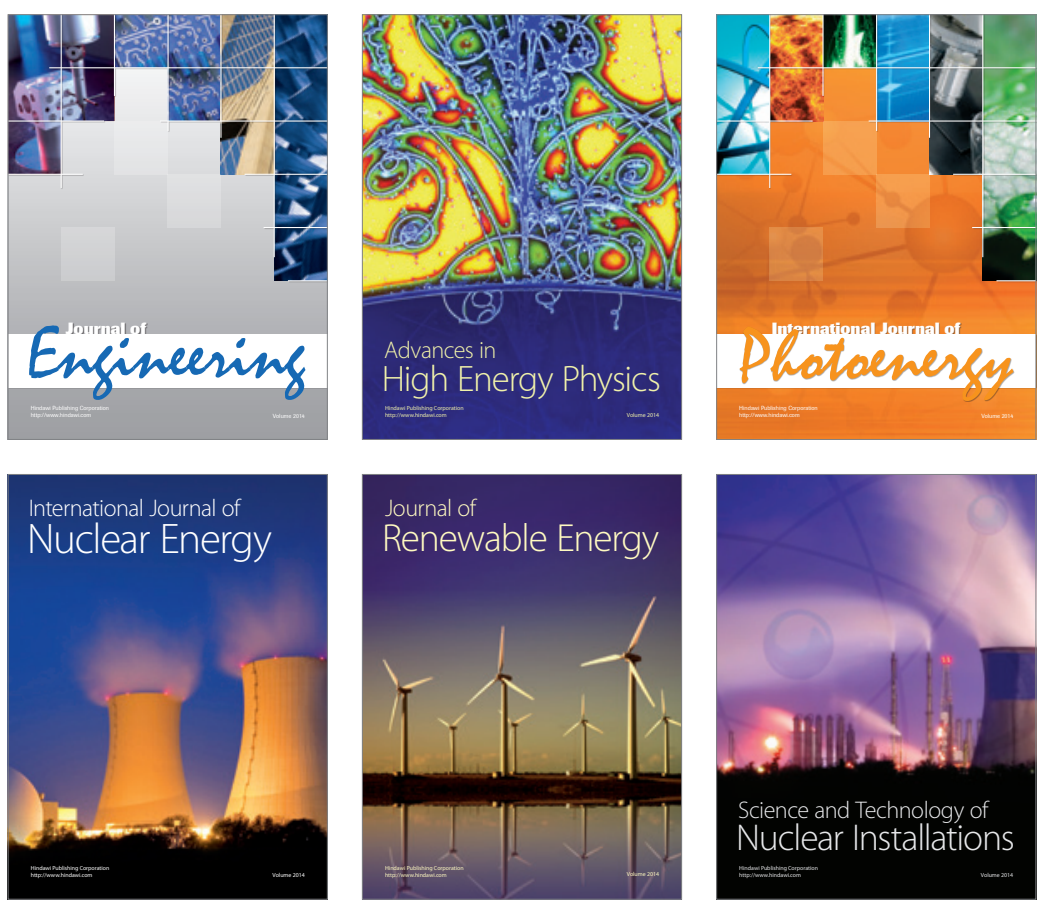
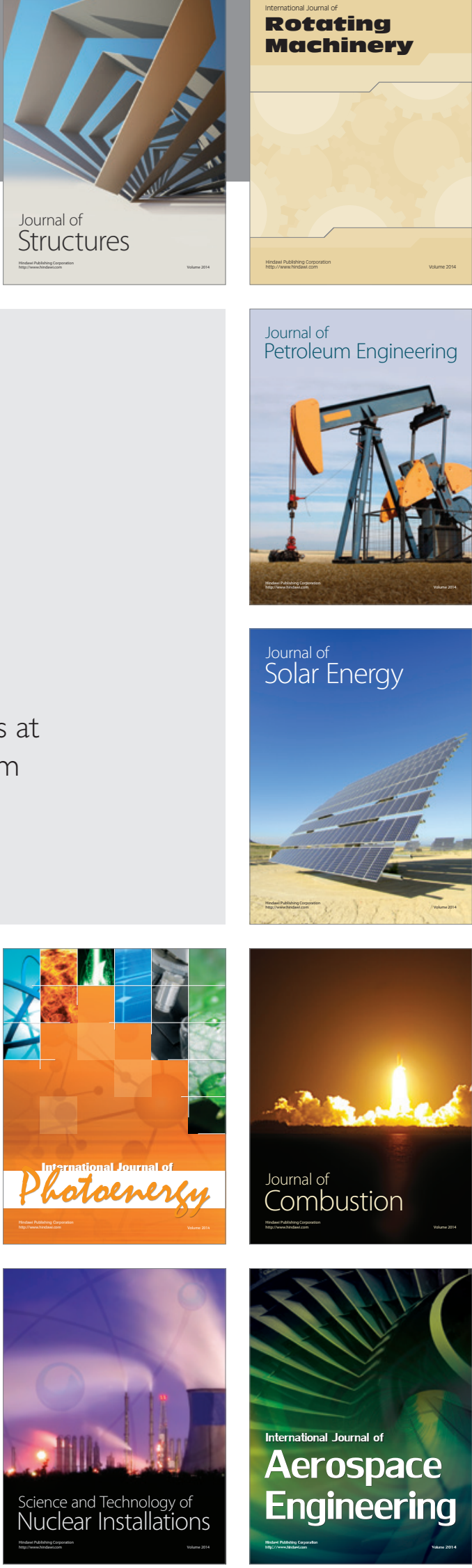